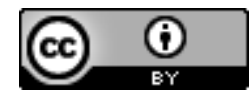

Esta obra está sob o direito de Licença Creative Commons Atribuição 4.0 Internacional.

\title{
A DISCIPLINA DA LEITURA NA VOZ DOS PAIS
}

\author{
Elizabeth Calheiros Borges ${ }^{1}$ \\ Audeluze Maria Araújo Victor De Mendonça Lopes ${ }^{2}$ \\ Sandra Maria Pontes ${ }^{3}$ \\ Adriana Cavalcante da Silva Lessa ${ }^{4}$
}

\begin{abstract}
RESUMO
A aprendizagem é um fenômeno social e cultural que se inicia bem antes da criança começar a frequentar o ambiente escolar. E é em seu lar, junto a sua família, em seu cotidiano e com seus hábitos que se iniciam a aprendizagem de uma criança. Esta pesquisa buscou analisar a produção científica sobre a relação entre os hábitos familiares da leitura e a influência que este pode ter no desenvolvimento da criança, analisando produções científicas publicadas entre 2015 e 2019, nos sites periódicos da SciELO, CAPES, MEDLINE, LILACS. Trata-se de uma revisão sistemática de literatura integrativa. Utilizando os descritores estruturados no DeCS e MeSH. O período de coleta de dados ocorreu entre setembro e dezembro de 2019. Adotou-se como critério de inclusão de artigos científicos e, como critérios de exclusão artigos que não contemplam a temática estudada. Espera-se poder compreender como a família pode influenciar no hábito da leitura de uma criança e principalmente em seu desenvolvimento.
\end{abstract}

PALAVRAS-CHAVE: Família. Hábito da leitura. Aprendizagem. Aluno.

\footnotetext{
${ }^{1}$ bethcalheiros@bol.com.br

2 del.fest@hotmail.com

3 sandrinha.2005@hotmail.com

4 adrianacavalcante32@hotmail.com
} 


\section{INTRODUÇÃO}

Sendo uma forma de linguagem, a leitura é um processo complexo, que se desenvolve gradualmente, segundo várias fases. É difícil, à primeira vista, elaborar uma definição consensual da mesma. A investigação tem procurado mostrar que a aprendizagem da leitura é um processo que se inicia informalmente, muito antes do seu ensino formal (GOUVEIA, 2009).

A leitura ajuda o leitor a respeitar a diversidade cultural, desenvolvendo uma visão mais abrangente da vida que o rodeia. Torna-se um ser mais rico pelo contacto com outras vivências e com outros mundos. Para satisfazer a curiosidade de saber mais sobre o que o rodeia, o homem adquire hábitos de leitura, procurando, por iniciativa própria, informações a fim de obter respostas (GOUVEIA, 2009).

Nas sociedades modernas e ocidentalizadas, as crianças tendem a iniciar o desenvolvimento da linguagem escrita antes da educação formal e a criança vive, mesmo antes de aprender a ler, práticas sociais de leitura (Azevedo, 2006; p. 325).

A vida quotidiana oferece diversas oportunidades de ler e de escrever, fazendo com que o contacto com o material impresso se processe de uma forma natural e espontânea na rua, no jardim-de-infância e na comunidade e sempre com a colaboração do adulto (GOUVEIA, 2009).

No contexto familiar, há a considerar não só o espaço físico como também as relações humanas que contribuem para a introdução das crianças no hábito e significado do impresso. A família é o primeiro modelo de identificação da criança, é ela que a confronta com materiais, lhe cria expectativas, lhe dá apoio e a estimula (Jolibert, 1991; p. 77).
Os autores citados demonstram a importância da leitura na vida da criança e como a família pode influenciar esta prática na vida de uma criança. Sendo a família o primeiro e o principal educador de uma criança seus hábitos ajudam no desenvolvimento e na aprendizagem escolar. Uma família que possui o hábito da leitura permitirá que a criança possa ter um melhor desenvolvimento em sua vida escolar.

\section{METODOLOGIA}

A presente pesquisa adotou como método a revisão sistemática, conforme as etapas expostas no Quadro 1, atendendo aos critérios como a definição do tema, pergunta norteadora, objetivo e estratégias de busca, além de dados lógicos da pesquisa, sites e bibliotecas acessados, descritores, string de busca, período de coleta dos dados e critérios de exclusão e inclusão dos artigos utilizados. 


\section{DETALHAMENTO DAS ETAPAS DA REVISÃO SISTEMÁTICA INTEGRATIVA.}

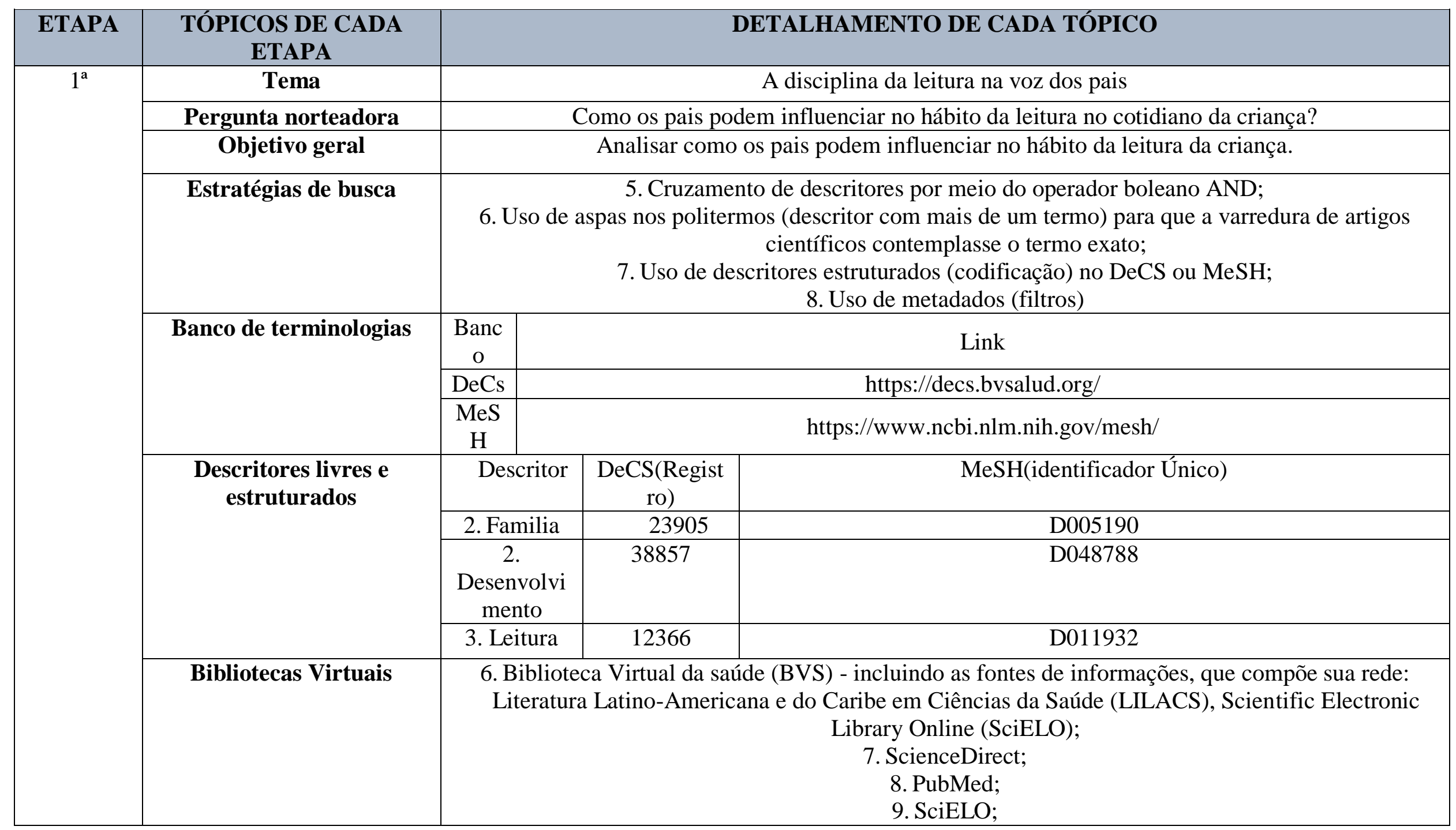






Fonte: elaborada pelos autores. 


\section{RESULTADOS}

Tabela 1 - Corresponde a quantidade das varreduras realizadas com cinco bases de buscas. Foram detectadas 3.379 publicações científicas nos bancos de dados, das quais 149 eram artigos científicos disponíveis após o uso dos filtros desses, foram feitos 17 downloads. Entretanto, obedeceram aos critérios inclusão 4 artigos científicos, sendo submetidos às etapas da revisão integrativa.

\section{Tabela 1}

String de buscas e bibliotecas virtuais consultadas

\begin{tabular}{|c|c|c|c|c|c|}
\hline $\begin{array}{c}\text { Descritores/ } \\
\text { String de busca }\end{array}$ & $\begin{array}{l}\text { Bases de } \\
\text { dados }\end{array}$ & $\begin{array}{c}\text { Total de } \\
\text { publicações } \\
\text { sem o filtro } \\
\text { "assuntos } \\
\text { principal" }\end{array}$ & $\begin{array}{l}\text { Textos } \\
\text { completos } \\
\text { após } \\
\text { aplicar } \\
\text { filtros }\end{array}$ & $\begin{array}{l}\text { Downloads } \\
\text { de textos } \\
\text { completos }\end{array}$ & $\begin{array}{c}\text { Textos } \\
\text { aproveitados } \\
\text { na Revisão } \\
\text { Sistemática } \\
\text { Integrativa }\end{array}$ \\
\hline \multirow{5}{*}{$\begin{array}{c}1^{o} \text { String } \\
\text { Leitura AND } \\
\text { desenvolvimento } \\
\text { cognitivo }\end{array}$} & Scielo & 50 & 8 & 5 & 3 \\
\hline & $\begin{array}{l}\text { Periódicos da } \\
\text { CAPES }\end{array}$ & 1.860 & 2 & 1 & 1 \\
\hline & $B V S$ & 388 & 9 & 1 & 0 \\
\hline & WILEY & 19 & 17 & 2 & 0 \\
\hline & ScienceDirect & 70 & 31 & 2 & 0 \\
\hline \multirow{5}{*}{$\begin{array}{c}2^{o} \text { String } \\
\text { Pais AND hábito } \\
\text { da leitura }\end{array}$} & Scielo & 0 & 0 & 0 & 0 \\
\hline & $\begin{array}{l}\text { Periódicos da } \\
\text { CAPES }\end{array}$ & 899 & 46 & 3 & 1 \\
\hline & $B V S$ & 21 & 1 & 1 & 1 \\
\hline & WILEY & 7 & 0 & 0 & 0 \\
\hline & ScienceDirect & 65 & 35 & 5 & 0 \\
\hline Total & & 3.379 & 149 & 20 & 6 \\
\hline
\end{tabular}

Fonte: Elaborado pela autora

Dos 4 artigos (quadro 1) analisados, os 4 eram estudos primários (sendo os 1 , uma pesquisa qualitativa, 2 estudos de caso e 1 revisão integrativa de literatura). Quanto ao ano publicado, foram selecionados apenas os publicados entre o ano de 2015 a 2019. Os artigos estavam escritos em português e inglês.
Já no Quadro 2, foram analisados 2 artigos, 2 eram estudos primários (sendo 1 estudo de caso e 1 revisão integrativa da literatura). Quanto ao ano publicado, foram selecionados apenas os publicados entre o ano de 2018 e 2019. Os artigos estavam escritos em português. 
QUADRO 01 - Descrição dos documentos (artigos) de acordo com os critérios de inclusão.

$1^{\circ}$ String - Leitura AND desenvolvimento cognitivo

\begin{tabular}{|c|c|c|c|c|c|}
\hline BASE & $\operatorname{AUTOR}(\mathbf{A})$ & TEMA & $\begin{array}{c}\text { DATA DE } \\
\text { PUBLICAÇÃO }\end{array}$ & $\begin{array}{c}\text { OBJETIVO DO } \\
\text { ESTUDO }\end{array}$ & CONCLUSÃO DO ESTUDO \\
\hline
\end{tabular}




\begin{tabular}{|c|c|c|c|c|c|}
\hline Scielo & $\begin{array}{l}\text { Naira } \\
\text { Muylaert; } \\
\text { Alicia } \\
\text { Bonamino; } \\
\text { Hilda } \\
\text { Micarello }\end{array}$ & $\begin{array}{l}\text { Habilidade de leitura } \\
\text { no ciclo de } \\
\text { alfabetização: uma } \\
\text { análise sobre a } \\
\text { igualdade de } \\
\text { conhecimento }\end{array}$ & 2019 & $\begin{array}{l}\text { investigar a noção de } \\
\text { igualdade de } \\
\text { conhecimentos proposta } \\
\text { por Crahay, a partir dos } \\
\text { dados3 de proficiência do } \\
\text { Programa de Avaliação } \\
\text { da Educação Básica do } \\
\text { Espírito Santo (PAEBES- } \\
\text { Alfa) referentes ao } 3^{\circ} \text { ano } \\
\text { do ensino fundamental, } \\
\text { etapa escolar que finda o } \\
\text { ciclo de alfabetização. }\end{array}$ & $\begin{array}{l}\text { Tais estudos podem favorecer a elaboração } \\
\text { de instrumentos de avaliação - itens e testes - } \\
\text { melhor ajustados à população avaliada e aos } \\
\text { objetivos da avaliação, contribuindo para } \\
\text { maior fidedignidade dos testes, ajustando-os } \\
\text { melhor ao construto que se está avaliando, e } \\
\text { assegurando a validade dos resultados } \\
\text { obtidos. Esses questionamentos podem e } \\
\text { devem servir de subsídios para a formulação } \\
\text { de políticas públicas, não apenas no campo } \\
\text { da avaliação educacional, mas também e, } \\
\text { principalmente, no campo do currículo, além } \\
\text { de suscitar novos estudos e desenhos de } \\
\text { pesquisa. }\end{array}$ \\
\hline Scielo & $\begin{array}{c}\text { Ana } \\
\text { Alexandre } \\
\text { da Silva } \\
\text { Souza; Ana } \\
\text { Regina de } \\
\text { Sena } \\
\text { Oliveira; } \\
\text { Felipe } \\
\text { Nunes } \\
\text { Batista }\end{array}$ & $\begin{array}{l}\text { A importância da } \\
\text { leitura como } \\
\text { atividade para o } \\
\text { desenvolvimento } \\
\text { cognitivo do } \\
\text { educando }\end{array}$ & 2015 & $\begin{array}{l}\text { observar metodologias } \\
\text { voltadas para leitura } \\
\text { analisando se essas } \\
\text { atividades tem influência } \\
\text { no processo de } \\
\text { desenvolvimento } \\
\text { cognitivo dos educandos } \\
\text { e quais suas concepções } \\
\text { norteadoras, no que se } \\
\text { refere à Educação } \\
\text { Infantil e à Educação } \\
\text { Especial, a fim de apoiar } \\
\text { nossas práticas de } \\
\text { mediação de leitura com } \\
\text { crianças, na escola }\end{array}$ & $\begin{array}{l}\text { Quando iniciamos a pesquisa para este } \\
\text { Trabalho de Conclusão de Curso, não } \\
\text { tivemos a intenção de propor ações às } \\
\text { professoras que se dispusessem a participar } \\
\text { no nosso trabalho. A nossa intenção era } \\
\text { somente aprender com elas. Qual não foi a } \\
\text { nossa surpresa quando constatamos que, } \\
\text { mesmo sem esta intenção de ampliar as } \\
\text { propostas desenvolvidas na escola, o nosso } \\
\text { trabalho causou uma reflexão sobre a prática } \\
\text { pedagógica das professoras. Consideramos } \\
\text { esse resultado bastante relevante, pois } \\
\text { entendemos que as profissionais perceberam } \\
\text { que além da teoria, da crença que a leitura faz } \\
\text { a diferença, a prática cotidiana da leitura com } \\
\text { as crianças mostra-se indispensável. }\end{array}$ \\
\hline $\begin{array}{l}\text { Periódicos } \\
\text { da Capes }\end{array}$ & $\begin{array}{l}\text { Silvana } \\
\text { Lúcia }\end{array}$ & $\begin{array}{l}\text { O cérebro que } \\
\text { aprende: uma }\end{array}$ & 2018 & $\begin{array}{l}\text { Apresentar os resultados } \\
\text { de uma pesquisa que }\end{array}$ & $\begin{array}{l}\text { O estudo realizado apontou que o incentivo } \\
\text { de práticas de leitura No entanto, torna-se }\end{array}$ \\
\hline
\end{tabular}




\begin{tabular}{|l|c|c|c|c|c|}
\hline & $\begin{array}{c}\text { Costabeber } \\
\text { Guerino; } \\
\text { Janaína } \\
\text { Pereira } \\
\text { Pretto } \\
\text { Carlesso. }\end{array}$ & $\begin{array}{c}\text { experiência com } \\
\text { práticas de leitura nos } \\
\text { primeiros anos de } \\
\text { escolarização }\end{array}$ & $\begin{array}{c}\text { visou verificar se os } \\
\text { projetos de incentivo à } \\
\text { leitura no cotidiano } \\
\text { escolar podem contribuir } \\
\text { de maneira importante no } \\
\text { desempenho de } \\
\text { estudantes nos primeiros } \\
\text { anos de escolaridade. }\end{array}$ & $\begin{array}{c}\text { fundamental para o professor promover os } \\
\text { estímulos corretos no momento certo para } \\
\text { que se possa integrar, associar e entender os } \\
\text { conteúdos propostos em sala de aula. Esses } \\
\text { estímulos quando emoldurados e aplicados no } \\
\text { cotidiano, podem ser transformadores em } \\
\text { uma aprendizagem significativa e prazerosa } \\
\text { no processo escolar. Sugere-se mais } \\
\text { pesquisas referente à temática estudada nesse } \\
\text { artigo, pois os projetos de incentivo a leitura } \\
\text { no âmbito escolar em diferentes níveis de } \\
\text { ensino da educação infantil ao ensino } \\
\text { superior, poderão contribuir para a produção } \\
\text { de novos conhecimentos, e ter reflexos } \\
\text { importantes no desempenho cognitivo dos } \\
\text { estudantes em outras disciplinas escolares, } \\
\text { além de contribuir para a formação do leitor- } \\
\text { literário crítico e reflexivo diante das } \\
\text { problemáticas sociais. }\end{array}$ \\
& & & \\
\end{tabular}

Fonte: Elaborado pela autora. 
$2^{\circ}$ string - Pais AND hábito da leitura

\begin{tabular}{|c|c|c|c|c|c|}
\hline BASE & AUTOR(A) & TEMA & $\begin{array}{c}\text { DATA DE } \\
\text { PUBLICAÇÃO }\end{array}$ & $\begin{array}{l}\text { OBJETIVO DO } \\
\text { ESTUDO }\end{array}$ & CONCLUSÃO DO ESTUDO \\
\hline
\end{tabular}




\begin{tabular}{|c|c|c|c|c|c|}
\hline & & & & & $\begin{array}{l}\text { desenvolvimento cognitivo-linguístico e da } \\
\text { comunicação oral e escrita. }\end{array}$ \\
\hline
\end{tabular}




\begin{tabular}{|l|l|l|l|}
\hline & & & $\begin{array}{c}\text { (Cruz, Ribeiro, Viana \& Azevedo, 2012). O } \\
\text { envolvimento do Educador, mas, } \\
\text { principalmente, da família na promoção da } \\
\text { literatura para a infância, é de extrema } \\
\text { importância dado que não só motiva as } \\
\text { crianças para este tipo de atividade, como se } \\
\text { cria um vínculo na relação adulto/criança, } \\
\text { enquanto a história está a ser lida/contada. Os } \\
\text { educadores não devem ter em conta apenas as } \\
\text { histórias que as crianças gostam ou o } \\
\text { propósito existente, mas também a forma e o } \\
\text { ambiente em que estas são contadas. Devem } \\
\text { existir estratégias de acordo com o grupo a } \\
\text { que a história se destina, os seus interesses e a } \\
\text { disposição para a ouvir. Neste sentido, ao } \\
\text { concluir o presente estudo, percebo que é } \\
\text { evidente a importância das histórias no Pré- } \\
\text { Escolar, dado que estas são essenciais no } \\
\text { desenvolvimento das crianças, pois } \\
\text { estimulam a sua compreensão, imaginação, } \\
\text { ampliam o seu vocabulário e fomentam o } \\
\text { interesse precoce pela leitura e escrita. }\end{array}$ \\
\hline
\end{tabular}

Fonte: Elaborado pela autora. 
Diante das conclusões expostas nos quadros acima, foi gerada a nuvem de palavras de acordo com constância de palavras que apareceu em seus textos (Figura 1), através da Plataforma online WordArt. O WordArt é um criador de arte em nuvem de palavras on-line, esta ferramenta agrupa e organiza graficamente as palavras-chave evidenciando as mais frequentes.

Figura 1 - Nuvem de palavras

Fonte: Elaborado pela autora
Mediante a Figura 1, foi possível constatar que as palavras em evidência na nuvem pertencem as categorias desenvolvidas a partir da análise de conteúdo de Bardin. Todas as categorias advêm da sua frequência (Tabela 2), que diz respeito ao seu quadro referencial.

De acordo com o objetivo deste estudo, preferiu-se por caracterizar as palavras que apresentaram maior frequência no escopo do texto e, a partir dos seus conteúdos semânticos, tinham uma magnitude expressiva no contexto das concepções alinhadas a temática estudada que é a influência da família no hábito da leitura, como destacado na Figura 1. Tabela 2 - Frequência das palavras presentes nos artigos publicados pelos internautas nas plataformas de bases científicas (BVS, WYLEI, SCIENCEDIRECT, PERIÓDICO DA CAPES, SCIELO).

Tabela 2

Frequência das palavras extraídas das conclusões dos artigos baixados das bases científicas.

\begin{tabular}{c|c|c} 
PALA VRAS & FREQUÊNCIA & CA TEGORIA \\
\hline Leitura & 49 & \multirow{2}{*}{ Família, hábito da Leitura e } \\
Desenvolvimento cognitivo. \\
\hline Criança & 44 & \\
\hline Desenvolvimento & 24 & \\
\hline Literacia & 17 & \\
\hline Conhecimento & 13 & \\
\hline Familiar & 12 & \\
\hline Educação & 12 & \\
\hline Aprendizagem & 11 & \\
\hline Pais & 10 & \\
\hline Cognitivo & 7 &
\end{tabular}

Fonte: Elaborado pela autora. 


\section{DISCUSSÃO}

Hoje se diz que pai e mãe passaram a dividir a tarefa de educar os filhos, o que parece louvável. Porém, no final do século XX, a família começou a desestruturar-se, em função de algo chamada "busca da qualidade de vida". Isso originou a defasagem no meio familiar das figuras parentais e, consequentemente, a desestruturação na educação dos filhos. Os pais foram em busca de melhores condições financeiras para suprir as necessidades básicas, esquecendo-se de, em muitos casos, participar da educação dos filhos. Essa tarefa foi atribuída à escola (CASARIN, 2007).

Porem, a atual sociedade tornou-se incontornável a importância do domínio completo do código escrito, nomeadamente das competências de leitura e de escrita. Vivemos num mundo imerso na leitura e na escrita, mesmo se tivermos em conta o mundo digital. Para ter acesso, por exemplo, ao universo da web, é necessário ser um leitor competente. E um leitor competente quer dizer um leitor capaz de ler fluentemente e com rapidez; um leitor capaz de compreender, na plenitude, aquilo que está a ler; um leitor que consegue aceder aos múltiplos significados explícitos e, sobretudo, implícitos de um texto. Só o acesso pleno à tessitura verbal, num exercício hermenêutico sobre o texto, possibilitará a reflexão, a crítica, a construção, num mundo que parece preferir o espírito acrítico e pouco dado à cogitação (BALÇA, AZEVEDO E BARROS, 2017).

Seguem abaixo, as categorias temáticas elaboradas a partir da revisão sistemática integrativa:

\section{A FAMÍliA E OS PATAMARES EDUCACIONAIS}

A família constitui instituição relevante no processo de reprodução social, que inclui a reprodução biológica e a tarefa de socialização, mediante a qual normas, valores e representações que organizam e dão sentido à vida social são transmitidos aos filhos.

Para realizar esse processo de reprodução, a família configura-se como grupo de convivência organizado por elementos culturais, no qual os interesses individuais de cada um de seus integrantes se conjugam com o interesse coletivo da unidade doméstica como um todo (ROMANELLI, 2010; SARACENO, 1994).

Enquanto grupo de convivência, a família organiza o consumo de bens materiais graças à cooperação econômica de seus componentes, que ocorre mediante a contribuição de ingressos monetários e também por meio da produção de valores de uso. A produção desses valores inclui tarefas domésticas, em geral realizadas por mulheres, as quais abrangem atividades como preparo de alimento, cuidados com as crianças, com a moradia e com a indumentária etc. (DURHAM, 2002, p. 209).

Mas a família é grupo onde também se consomem bens simbólicos, isto é, representações diversas, pois é na unidade doméstica que "se concentram informações sobre a sociedade e onde se elabora a interpretação dessas informações" (DURHAM, 2012, p.210).

Por isso, a vida doméstica não é meramente instância de reposição do instituído, mas configura-se como espaço de reelaboração das representações sobre a esfera pública, e envolve o modo como os indivíduos interpretam, dentre outros, o universo do trabalho, da política, do sistema educacional, da religião, do lazer. 
A convivência entre os integrantes da família é um processo de recriação tanto de representações quanto de formas de relacionamento e de busca de novas estratégias de sobrevivência para enfrentar dificuldades como ocorre com famílias de classes populares.

Essas classes podem ser consideradas como constituídas pela população pobre dos centros urbanos, que vive em condições financeiras precárias, decorrentes da reduzida qualificação ocupacional e da baixa escolaridade de seus integrantes, que têm acesso limitado aos serviços públicos, como educação e saúde. (ROMANELLI, 2010, p. 375)

A importância do rendimento do trabalho dos filhos para assegurar o consumo de bens e serviços necessários à sobrevivência e reprodução do grupo doméstico foi documentada em estudos sobre as classes populares (SILVA, 2008, p. 37).

Esses estudos também apontam a importância que as famílias das classes populares atribuem à escolarização dos filhos, a qual resulta da representação que pais e filhos fazem da escola e do mercado de trabalho.

Isto é, a possibilidade de se conseguir emprego e melhores colocações no interior das empresas está associada, nas representações da família, ao acesso ao ensino público - fundamental e médio - o que é considerado pelos integrantes da unidade doméstica como um direito social que o Estado tem obrigação de garantir a todo cidadão.

É nesse quadro de experiências vividas pelas famílias de classes populares que se pode situar a relação dos adolescentes - enquanto estudantes e trabalhadores, isto é, co-provedores do consumo doméstico - com o sistema de ensino e com o mercado de trabalho.

Como os antropólogos já demonstraram (Benedict, 1965), a adolescência não é vivida de um único modo em todas as sociedades. Embora não haja uniformidade quanto aos limites etários que delimitam a adolescência, ela é situada entre 12 e 18 anos, de acordo com o Estatuto da Criança e do Adolescente ECA, e entre 10 e 19 anos, como sugere a OMS - Organização Mundial de Saúde (2009).

A oscilação nesses limites deve-se ao fato de que o critério etário não pode ser tomado isoladamente para caracterizar essa fase, já que:

Nós sabemos hoje que as idades da vida, embora ancoradas no desenvolvimento biopsíquico dos indivíduos, não são fenômeno puramente natural, mas social e histórico, datado, portanto, e inseparável do lento processo de constituição da modernidade, do ponto de vista do que ela implicou em termos de ação voluntária sobre os costumes e os comportamentos (PERALVA, 2010, p. 15).

Deixando de lado o critério exclusivo da idade, pode-se considerar essa fase a partir da emergência de novas formas de sociabilidade dos adolescentes com diferentes esferas da vida social, quando passam a viver sentimentos conflitantes e procuram autonomia e independência diante dos pais e dos adultos e amparo no grupo de pares.

Nesse processo, caracterizado como um período de revisão, autocrítica e transformação, de vital importância para o desenvolvimento da personalidade (Coleman, 2012, p. 18), o adolescente, lentamente, constrói sua identidade e, de simples espectador, assume postura mais questionadora e ativa em relação aos 
diferentes contextos sociais de que participa.

Nas sociedades capitalistas ocidentais a adolescência constitui uma fase de transição conturbada, que tende a prolongar-se, inclusive nos países economicamente mais desenvolvidos (UNESCO, 2010).

No Brasil, onde a desigualdade social convive com a diversidade cultural, a adolescência apresenta características específicas, que variam de acordo com a camada ou classe social, com o gênero, com o período histórico e com a cultura em que o adolescente está inserido (ALVESMAZZOTTI, 2012, p. 16).

\section{O ACOMPANHAMENTO DA FAMÍLIA NA VIDA ESCOLAR DA CRIANÇA}

Devido às exigências atuais, os pais logo cedo colocam seus filhos em creches ou entregues a babás. Chegam em casa exaustos de um dia de trabalho, têm ainda as lides domésticas ou trazem trabalho para casa. A criança é colocada sozinha a ver televisão ou a brincar sem um adulto que lhe dê atenção. A relação familiar centra-se prioritariamente nas necessidades físicas da criança, ou seja, na alimentação, na higiene, no descanso (MANSINE, 2015 p. 26)

Desde criança que as novas tecnologias imediatamente as seduzem e permitem a aquisição de novos saberes. $\mathrm{O}$ seu conhecimento vai progredindo através das informações que recebe do meio onde se insere, do meio familiar, do grupo de pares, da escola, dos meios audiovisuais, dentre outros.

Enquanto jovens, o lazer e o convívio com os colegas têm uma importância primordial no seu processo de socialização e formação. Machado (MANSINE, 2015, p. 35) afirma que as culturas juvenis são fortemente viradas para o lazer, de certa forma em oposição ao saber tradicional da escola e da família, que privilegia a ordem e a certeza, o ensino e a transmissão de conhecimentos e experiências entre pares.

Embora haja uma certa continuidade na transmissão de valores de pais para filhos, a verdade é que os jovens de hoje adquirem a sua identidade não só dentro, mas também fora da família, através de discursos variados que a escola e a família poderão ou não integrar. Todavia, a família não se pode demitir do seu papel e atribuir responsabilidades aos outros agentes educativos na formação dos seus descendentes.

A iniciação da vida escolar é uma das mudanças fundamentais que ocorrem na vida da criança. $O$ ingresso na escola tem acontecido cada vez mais cedo. Nela, os alunos passam várias horas por dia, durante um longo período de suas vidas. Através desta mudança, a criança cria vínculos com outros adultos, como os professores, e passa a relacionar-se com outras crianças. Desta forma, a escola incorpora o papel familiar de educação da criança durante todas as etapas de seu desenvolvimento, traduzindose numa nova transformação sociocultural (ALVES- MAZZOTTI, 2012, p. 20).

A sociedade vem atribuindo a escola, seja de forma tácita ou não tarefas que antes eram restritas a família. A escola ganhou o papel de transmissora de normas de conduta e valores culturais. Todavia, escola e família se complementam, cada qual com seus papéis distintos.

A família fica com a responsabilidade de transmitir valores, normas de comportamento da cultura e de padrões. A escola ficou com o dever de ensino- aprendizagem de conteúdos sistematizados e aprendizagem de 
habilidades sociais saudáveis tanto no universo escolar como na sociedade como um todo. (MONTANDON E PERRENOUD, 2011, p.154)

Muitos educadores reclamam do desinteresse dos pais para com a educação dos filhos. As reuniões entre pais e mestres mostram essa triste realidade. Faz-se necessária à presença da família nas instituições de ensino. Os pais precisam frequentar a escola onde seus filhos são educados.

Como dizem Montandon e Perrenoud (2011, p.155), “de uma maneira ou de outra, onipresente ou discreta, agradável ou ameaçadora, a escola faz parte da vida cotidiana de cada família".

Os educadores têm sentido dificuldade em aceitar as novas atribuições oriundas das mudanças sociais e familiares e de incorporar as novas demandas no desenvolvimento de seu trabalho. Pois muitas famílias não percebem mais o papel da escola como agência transmissora de conhecimentos sistematizados e têm imputando a ela a tarefa mais ampla de educar para a vida.

Criar relações mais estreitas com os pais, pode fazer com que eles compreendam melhor o trabalho da escola. Espera-se que, dessa forma, se envolvam mais no processo educacional dos filhos. Se a escola e a família falarem a mesma língua, pode ser possível que as crianças consigam ter uma aprendizagem mais significativa, um percurso acadêmico mais tranquilo e um desenvolvimento intelectual e emocional mais harmoniosos (PILÃO, 2015, p. 22).

A escola tem buscado estabelecer relação com a família visando $\mathrm{o}$ investimento familiar e pessoal de cada aluno na aprendizagem escolar, e na adoção de padrões de comportamento por ela valorizada. Porém, nem sempre se consegue alcançar os resultados almejados nessa tentativa de controle à distância.

Entre as dificuldades encontradas no estabelecimento de relações harmoniosas pode-se citar a forma geralmente adotada pela escola para estabelecer esse contato: além de serem unidirecionais parte quase sempre da escola em direção às famílias predominam nas situações de baixo rendimento escolar e de mal comportamento das crianças. (PILÃO, 2015, p. 22).

Isso ocorre certamente porque os educadores muitas vezes pensam que lhes cabe ensinar e que às famílias compete solucionar as dificuldades que enfrentam em sala de aula no contato diário com os alunos, sejam eles referentes à sua aprendizagem ou às suas atitudes.

Os professores, algumas vezes, se esquecem de que a maior parte dos casos, a indisciplina e o desrespeito estão relacionados ao tratamento que dão aos alunos e ao conteúdo desenvolvido. Apesar de solicitarem o apoio das famílias nessas situações conflituosas os professores geralmente resistem às interferências familiares, especialmente se essas se direcionarem aos temas que ensinam, ao seu fazer pedagógico e, muito especialmente, se a interação é iniciada pelos pais. (ALVESMAZZOTTI, 2012, p. 23).

Apesar de regidas pela mesma legislação apresentarem as mesmas metas, as escolas não são todas iguais, bem como as famílias. Todavia, apresentam entre si várias semelhanças.

Essas diferenças, que tornam cada família e cada escola unidades idiossincráticas, devem ser consideradas como casos particulares, que, ao serem compreendidos em sua unicidade, possibilitam ultrapassar suas particularidades para atingir o objetivo que 
têm em comum e que está, em princípio, relacionado à busca de melhor qualidade da aprendizagem escolar dos alunos (PERALVA, 2010, p. 38).

Sendo assim, cada comunidade, cada escola e cada família deve ser estudada em suas particularidades, para que os caminhos de interação produtiva possam ser trilhados e seus papeis bem definidos em benefício dos interesses do alunado.

A confiança entre pais e filhos pode ser estabelecida ao se criar um ambiente familiar onde exista comunicação afetiva e aberta, onde aja diálogo e se proporcione à proteção e motivação. Com a motivação capacidade de mobilização para um determinado objetivo o aluno se sente impulsionado ao aprendizado, que conduz o aluno ao sucesso escolar (PERALVA, 2010, p. 39).

Quando o aluno se sente motivado a aprender, ele constrói sozinho palavras e frases, em contrapartida, aquele que se encontra sem motivação vai encontrar grandes dificuldade e ter constantes insucessos no processo de aprendizagem. Muitas crianças se sentem desmotivadas com os conteúdos escolares, pois a escola impõe-lhes tarefas que não tem sentido, não conseguem enxergar naquilo uma prática útil para o cotidiano.

Os pais precisam participar dessa dinâmica com os filhos: ir as reuniões, manter contato com a professora $\mathrm{e}$ acompanhar os conteúdos, valorizando a sua aprendizagem e dando-lhes um significado. É preciso que os encoraje e os elogie. O resgate de valores morais de respeito à vida, solidariedade, fraternidade, liberdade e justiça, pode ser uma arma nas mãos dos educadores no combate a violência, garantindo os direitos desses pequenos cidadãos (ALVES-MAZZOTTI, 2012, p. 17).
Desta forma, educadores devem se unir à família, ao Estado e a sociedade visando o resgate do ensino de qualidade. Cabendo ao Estado o dever de garantir uma formação sólida para os educadores, além de uma profunda mudança nas questões do ensino.

A sociedade cabe a função de acolher o jovem de forma democrática dando-lhe o direito de se expressar. Aos educadores cabem a constante reciclagem $\mathrm{e}$ o compromisso de criar um ambiente saudável em sala de aula. E aos pais fica o dever de dar um rumo aos seus filhos, participando ativamente de todas as etapas de suas vidas.

\section{OS PROTAGONISTAS DA HISTÓRIA ESCOLAR}

Segundo Grossi e Bordim (2012 p.158), os protagonistas da história da aprendizagem escolar são o professor e o aluno, com a participação da família e da comunidade. Estes grupos podem funcionar como facilitadores ou inibidores no processo de desenvolvimento afetivointelectual da criança. É relevante o papel do professor, que, em contato com o aluno constitui o pólo mais significativo do processo ensino-aprendizagem. É nova a ideia de que a ação educativa e, em particular, o ofício do professor é uma prática relacional e institucional.

Em nosso estudo, a relação professor-aluno é enfocada numa perspectiva "construtivista do conhecimento" onde ao educador cabe agir como facilitador das relações e problematizador das situações de aprendizagem e o aprender significa a reconstrução ativa das soluções dos problemas, o que inclui, fundamentalmente, uma dimensão pessoal e criadora. 
Cabe ao professor, além de apresentar elementos a serem conhecidos, a tarefa de mobilização para o conhecimento, ou seja, de um modo geral, na situação pedagógica, o interesse precisa ser provocado.

Algumas vezes a chama do desejo do aluno pelo aprendizado escolar pode estar baixa ou desorganizada, sendo, nesse espaço, onde o educador necessita intervir no sentido de reavivá-lo e transformar atitudes destrutivas em atitudes construtivistas.

Grossi e Bordim, (2012 p.159,) coloca: "O professor precisa conhecer cada aluno, investigar e compreender quais as suas dificuldades e o que cada um pode oferecer de positivo. Precisa ter a arte de reagir às diferenças".

Com o objetivo de melhorar o desempenho geral da criança o professor pode oferecer ensino suplementar em certas disciplinas (conforme necessidade do aluno), fazer encaminhamentos para tratamento com especialistas (de acordo com o caso). No entanto, um dos modos pelos quais o professor pode constituir ajuda construtiva para o aluno é aumentando as oportunidades legítimas de atenção.

O professor pode ajudá-lo encorajando-o, elogiando-o por suas realizações e estimulando a sua independência. $\mathrm{O}$ professor atento estará consciente de que poderá ter seus alunos efetivamente em aula, com ele, para aprenderem, se seus desejos aí estiverem, para que aí estejam, deve haver uma falta para a inteligência (HOFFMAN, 2013, p.39).

Do ponto de vista cognitivo, provoca-se esta falta, mediante criação de situações motivadoras: aguçando a curiosidade, colocando o assunto com clareza, ligando conhecimentos e a experiência que o aluno traz, propondo um roteiro de trabalho, formulando perguntas instigadoras. O professor atento procurará dar a criança considerada desinteressada algum senso de realização. Para isso valerse á sobretudo de algum talento ou interesse especial da criança.

Possivelmente, a estimulação de talentos não escolares pode facilitar o ajustamento de muitos alunos à escola, pois pode proporcionar-lhes experiências de sucesso, fato importante para a formação de um autoconceito mais positivo. "É importante que o professor procure construir uma prática que respeite o princípio de confiança máxima na possibilidade de o educando vir a aprender" (HOFFMAN, 2013, p.40).

A expectativa do professor, a confiança manifesta da capacidade do aluno, o atendimento individual e a ajuda constante contribuem para o despertar do interesse em relação ao ensino e à escola.

Por outro lado, segundo Hoffman (2013, p.40), existem diversos fatores que podem contribuir para o desinteresse do aluno pelo aprendizado escolar, tais como:

A escola pode não se apresentar como fonte de interesse para o aluno, por não oferecer conexão lógica com a realidade mais imediata dele. Seu currículo programático motiva muito pouco o aluno. Estabelece a separação entre o espaço do aprendiz e o da existência;

- Conteúdos que são trabalhados de forma inadequada e no momento inoportuno sem leve à aprendizagem costuma gerar resistência àquele objeto de conhecimento, em função das experiências negativas vivenciadas pelo aluno anteriormente;

A escola que adota uma concepção autoritária negando e castrando a 
expressão do desejo e a criação do educando e do educador, fazendo do educando um mero repetidor de conhecimentos e de desejos, pois não lhe é dada a oportunidade de revelar o que pensa, discutir suas ideias e elucidar suas dúvidas (HOFFMAN, 2013 p.40).

Sabe-se, que o grau de satisfação ou insatisfação do docente, as suas expectativas e o tipo de relacionamento mantido com os alunos são variáveis que podem contribuir de maneira positiva ou negativa tanto para um bom desempenho escolar quanto para o desenvolvimento psicossocial do sujeito em desenvolvimento.

As expectativas do professor de acordo com Hoffman (2013, p.41), em relação ao desempenho escolar do aluno construídas a partir de uma série de variáveis: Primeiras impressões que o professor tem do aluno, o conhecimento da história escolar do mesmo, a aparência a atração física do aluno.

Pesquisa realizadas por Clifford e Walter em 1973 (apud ALENCAR, 2010, p.136) demonstram que crianças atraentes tendem a ser julgadas pelo professor como mais interessadas na escola, mais inteligentes, mais populares, com mais probabilidade de serem bem-sucedidas.

As expectativas negativas do professor em relação ao sucesso escolar da criança, muitas vezes criam situações em sala de aula que resultam em ansiedade, embaraço ou sentimentos de fracasso por parte do aluno.

"Experiências contínuas de fracasso escolar tendem a afetar negativamente o interesse pela aprendizagem e provocar o isolamento, depressão e uma reação defensiva de extrema agressividade e insubordinação bem como produzir baixos índices de auto-estima" (ALENCAR, 2010, p.151).

No cotidiano escolar, observa-se certos procedimentos por parte do professor que podem contribuir negativamente para uma boa aceitação do aluno pelo aprendizado escolar, Incutir no aluno, por palavras ou ações, que nada que ele possa fazer o conduzirá ao sucesso; Fazer prognósticos absurdos e atemorizantes a respeito do desempenho do aluno; Comparar publicamente um aluno de maneira desfavorável em relação aos outros; Acomodação do professor quando prefere o sossego em vez de enfrentar as dificuldades apresentadas pelos alunos. (ALENCAR, 2010, p.151).

É frequente o professor deixar os alunos considerados mais fracos ou desinteressados entregue às suas próprias dificuldades, dedicando-se, especialmente, àqueles que para ele têm condições de apresentar desempenho superior.

Pesquisadores nesse campo, Kaumim e Gump, (apud ALENCAR, 2010, p.38), "constataram que os alunos de professores punitivos apresentavam um maior grau de agressividade, eram mais inquietos, tinham ideias mais conflitantes a respeito de comportamentos desviantes na escola, além de serem menos interessadas com relação à aprendizagem e valores escolares".

Aspy e Buhler (apud ALENCAR, 2010, p.140), constataram que os alunos cujos professores gozavam de um autoconceito mais positivo apresentavam um progresso escolar substancialmente maior do que aqueles cujos professores tinham um autoconceito mais negativo.

Carl Rogers (2010, p. 37) em seu livro "Liberdade para Aprender em Nossa Década" enumera algumas características ideais para um facilitador da aprendizagem: 
A autenticidade do facilitador (ser ele mesmo sem medo de demonstrar seus reais sentimentos); Atitude de apreço, aceitação e confiança (apreço pelo estudante como ser humano imperfeito com muitos sentimentos e potencialidades); Compreensão empática (encara o mundo através dos olhos do estudante sem avaliá-lo ou julgá-lo). Porém, ele acredita na dificuldade do professor apresenta-se de forma enumerada acima, pelo fato de maior parte dos professores não ter nenhuma oportunidade ou bem poucas de aprender modos mais individualizados de lidar com crianças.

$$
\text { Informações sobre o }
$$

desenvolvimento da afetividade e da inteligência muitas vezes não figuram no cenário dos cursos na formação de professores, fato que contribui para a dificuldade, por partes destes, da observação do aluno como uma totalidade e isto interfere significativamente na atividade docente (COSTA, 2014, p. 18).

É importante observarmos que, na atualidade, as bases da motivação tradicional tendem a cair na medida em que a escola já não é mais a única fonte de conhecimento, nem está sendo reconhecida como fator de ascensão social como antes.

Os educadores estão submetidos a um alto grau de solicitação em função da infinidade de estímulos da sociedade contemporânea (TV, rádio, internet, outdoor) jornais, revistas e atividades extracurriculares, etc. Portanto, é grande o desafio do educador no sentido de superar a usual dispersão dos alunos em relação, aos objetivos de conhecimentos apresentados pela escola, pelo fato do inimigo maior: o processo de alienação imposto pela sociedade. (COSTA, 2014, p. 13).

De acordo com Veiga (2014, p. 41), o primeiro passo do educador, enquanto articulador do processo de aprendizagem deverá ser no sentido de conhecer a realidade com a qual vai trabalhar (alunos, família, escola, comunidade), considerando o fato de que toda aprendizagem tem seu habitat no convívio com os outros e envolve sempre um tripé: quem aprende o que se aprende e o outro.

O educador também precisa estar consciente da necessidade de propiciar ao aluno uma aprendizagem significativa, que implica em buscar conhecimento vinculado às necessidades, interesses e problemas oriundos da realidade do educando e da realidade social mais ampla.

Significar um objeto de conhecimento, para que o sujeito se debruce sobre ele, implica numa ação educativa no sentido de provocar, desafiar, estimular, ajudar o sujeito a estabelecer uma relação pertinente com o objeto que corresponda, em algum nível à satisfação de uma necessidade sua: intelectual, afetiva, ética, física, lúdica, estética, espiritual, econômica, política, social e cultural. (ALENCAR, 2010, p.153).

A aprendizagem significativa depende do nível de representação e da carga afetiva envolvida. Envolve tanto os pensamentos inconscientes quanto as sensações e combina o lógico e o intuitivo.

Para Piaget e os pós-piagetianos, as estruturas do pensamento, do julgamento e da argumentação são o resultado de uma construção realizada por parte da criança em longas etapas de reflexão, de remanejamento. Essas estruturas são resultantes da ação da criança sobre o mundo e da interação da criança com seus pares e interlocutores. (ALENCAR, 2010, p.153).

Piaget, em sua teoria da Epistemologia Genética, baseou-se na concepção construtivista que enfatiza a capacidade do sujeito de integrar 
informações e processá-las, valoriza o agir do indivíduo no processo de construção do conhecimento, sendo esta construção um processo contínuo na busca constante do equilíbrio. Esta noção de equilíbrio é o alicerce da teoria de Piaget.

Para ele, todo organismo vivo procura manter um estado de equilíbrio ou adaptação com seu meio, agindo de forma a superar perturbações na relação que estabelece com o mesmo. Qualquer modificação, por mínima que seja, orgânica ou de alguma característica do meio ambiente provoca um desequilíbrio. Neste momento os mecanismos de assimilação e acomodação são acionados para que seja alcançado novo estado de equilíbrio. (ALENCAR, 2010, p.151).

Através da assimilação o organismo desenvolve ações destinadas a atribuir significações, a partir de sua experiência anterior, aos elementos do ambiente com os quais interage.

Através da acomodação o organismo tenta estabelecer um equilíbrio superior com o meio. Neste momento o organismo é impelido a se modificar para se ajustar às demandas impostas pelo ambiente. A assimilação é, portanto, o primeiro passo para o aprendizado. É o momento em que se entra em contato com o novo. Diante desse novo, o organismo sofre um desequilíbrio e busca uma forma de incorporá-lo. Somente quando ele acomoda, ou seja, quando modifica suas estruturas internas num esforço assimilado, é que ocorre a aprendizagem real (ROMÃO, 2012, p.24).

Numa visão piagetiana, “a aprendizagem pressupõe experiências vividas pelos sujeitos o que torna os elementos da ação educativa, únicos e individuais em seus entendimentos e desentendimentos apesar de sofrerem um mesmo processo educativo" (HOFFMAN, 2013, p.45).

De acordo com esta visão deixa-se de buscar os culpados para o fracasso escolar e procura-se razões lógicas e cientificas para tal fato.

A abordagem vygotskyana, conhecida como sócio histórica do desenvolvimento humano, dirige-se à questão da construção das funções psicológicas no homem, trabalhando com conceitos de mediação na relação homem/mundo, e com papel fundamental do contexto cultural na construção do modo de funcionamento psicológico dos indivíduos. (VASCONCELOS, 2010, p.45).

Com referência ao aprendizado escolar, Vygotsky apresenta a hipótese da "zona de desenvolvimento proximal" que se situa entre o nível de desenvolvimento real do aluno caracterizado pela solução independente de problemas e o nível potencial que é determinado pela resolução de problemas com a orientação de um adulto ou com a ajuda de um colega.

Numa perspectiva dialética "O conhecimento é constituído pelo sujeito na sua relação com o outro e com o mundo" (VASCONCELOS, 2010, p.45). Isto significa que o conteúdo apresentado pelo professor precisa ser trabalhado, refletido, reelaborado pelo aluno, para se constituir em conhecimento dele.

A fim de que o objeto de conhecimento proposto pelo professor torne-se objeto de conhecimento para o aluno, é necessário que este, enquanto ser ativo que é, esteja motivado para isso, dirija sua atenção, seu pensar, seu sentir, seu fazer sobre o objeto de conhecimento.

Freire afirma: "Ninguém motiva ninguém, ninguém se motiva sozinho, as pessoas se motivam em comunhão, 
mediadas pela realidade" (apud VASCONCELOS, 2010, p.54).

A motivação para o conhecimento em sala de aula, além das características do sujeito, está relacionada ao assunto a ser tratado, à forma como é trabalhado, às relações interpessoais (professor $\mathrm{x}$ aluno, aluno $\mathrm{x}$ aluno) entre outros.

Os fatores motivacionais e afetivos constituem uma dimensão do processo de aprendizagem que devem ser levados em conta. A carga afetiva pode atribuir ou inibir o crescimento intelectual e emocional do indivíduo dependendo de como é trabalhado. Para aprender, a pessoa precisa querer, deve sentir necessidade.

A afetividade parece destinar nossas condutas em relação aos sujeitos. Eventos do dia-a-dia nos ensinam que o encorajamento, uma acusação, um tom de voz, um olhar, uma atitude de desprezo, são suficientes para modificar nosso equilíbrio interno, afetar nossa moral.

Qualquer um de nós tem a experiência de como nossa capacidade de concentração, de trabalho, de reflexão, se alteram na dependência de nossos estados emocionais. "Quando se consegue uma modulação adequada a nível de ansiedade, a capacidade criativa, o aprender significativos tornam-se ampliados". (SCOZ, 1992 apud ARAÚJO, 2014, p. 22).

$\mathrm{Na}$ medida em que se aprende o objeto do conhecimento, constata-se a ignorância, surgem novas perguntas, continuando-se, assim, a busca de novos conhecimentos. Ambos os circuitos, o do desejo e o da inteligência, enfrentam-se com a falta e com a carência.

Segundo Fernandes (2014, p.86):

Nós temos a psicanálise que nos ajuda a entender os processos inconscientes do homem, temos as teorias da inteligência de Piaget, mas ainda não se construiu alguma teoria que seja específica e única para o entendimento do processo de aprender.

Portanto, ao estudarmos o processo de aprendizagem, precisamos considerar os aspectos que implicam "no aprender" o organismo, o corpo, a inteligência e o desejo, levando em conta que todo sujeito tem sua história, suas necessidades, interesses, sua maneira de aprender, ou seja, meios, condições e limites próprios. Para ela, "a aprendizagem é uma função que participam tanto a estrutura inteligente como a estrutura desejante, ambas inconscientes".

A psicopedagoga Pain (2012, apud Sampaio, 2014, p. 43) centrou seus estudos nos Distúrbios de Aprendizagem e apresenta uma contribuição significativa para o estudo da conjunção entre os polos que envolvem o mundo do conhecimento objetivo e o mundo da subjetividade e o faz a partir da vertente psicanalítica. Ao observar crianças com problemas de aprendizagem, evidenciou a presença de uma articulação que liga significativamente o potencial intelectual afetado e a dramática inconsciente na qual a criança estava comprometida.

Para ela, as "perturbações nos processos de aprendizagem constituem expressivo motivo de consulta para reflexão acerca da possível articulação entre uma teoria do sujeito capaz de esquecimento, equívoco e ignorância (mundo subjetivo)" (MOKREFS, apud CHAVES, 2013, p.73).

Freud e Piaget deram significativas contribuições à nossa compreensão da criança, pela descrição da Psicologia e do Desenvolvimento dos conhecimentos e das emoções. Enquanto a psicologia de Freud é quase exclusivamente centrada nas emoções e apoie sua interpretação na 
realização dos desejos, a de Piaget é centrada na inteligência e apoia sua interpretação na lógica da ação.

Emoção e intelecto são geralmente vistos como comportamentos psicológicos separados em nossas vidas pessoais e instituições sociais. Eles são frequentemente considerados como forças antagônicas trabalhando uma contra a outra. Para a Psicanálise, a inteligência emerge a partir de um apoio sobre os "restos sexuais" (grifo nosso). É nesse ponto que se situa uma diferença radical da teoria Psicanalítica em relação a qualquer teoria cognitiva sobre o desenvolvimento da inteligência. (ALENCAR, 2010 p.153).

Embora a Psicanálise e a teoria da Epistemiologia Genética divirjam uma da outra em suas respectivas ênfases uma, ressaltando o vínculo emocional libidinal entre duas pessoas e a outra, a construção cognitiva da pessoa em face de um objeto de conhecimento, observamos uma aproximação das Psicologias de Freud e Piaget no conceito de objeto, pois, para ambos os estudiosos, o objeto, seja o objeto de vínculo ou objeto de conhecimento, implica em relações pessoais de parte dos agentes que constroem esses objetos. (PERALVA, 2010, p. 25).

Os objetos de conhecimento e de desejo não são nada mais que os dois lados da mesma moeda.

Apesar das tentativas de se fazer articulações entre a Psicanálise e a teoria piagetiana, ainda está faltando, entretanto, para uma frutífera compreensão de qualquer teoria que conceitualize o sujeito e seus processos de aprendizagem, um quadro global que ligue diretamente conhecimento e emoções. (ALENCAR, 2010 p.154).

O psicopedagogo cujo objeto de estudo é o trabalho com a problemática da aprendizagem, não pode deixar de observar o que acontece entre os aspectos cognitivos (memória, inteligência, atenção, percepção...) e os desejos inconscientes.

Este profissional também precisa observar se os distúrbios de aprendizagem são consequências de causas externas à estrutura familiar e individual (problemas de aprendizagem reativa) ou de causas internas, constituindo-se num sintoma, que vem a ser uma reação positiva da personalidade para que possam ser elaborados planos adequados de intervenção pedagógica.

\section{A FAMÍlIA COMO ESPELHO DO ALUNO}

A importância da família como força modeladora do sujeito em desenvolvimento é apontada por estudiosos de diferentes ciências, cabendo à família a socialização da criança e a transmissão de valores, crenças e costumes nos quais se acha inserida. Portanto, se faz necessário que investiguemos a família para, através dela, reconstruirmos a história do sujeito.

A família, segundo Grossi (2013 p.222):

É um grupo social básico do ser humano, onde as experiências vividas nesse grupo vão influenciar a construção da individualidade e a identidade do sujeito. Assim, a família poderá corresponder primordialmente, em nível individual, à instância do desejo.

Pode-se observar o valor que a família dá ao aprendizado escolar de seus filhos, o que representa esta criança para a família, quais as expectativas desta família em relação ao futuro profissional de seu filho, bem como, observarmos o tipo de atendimento que foi dado à criança nos seus primeiros anos de vida. 
Com base nesses primeiros contatos entre a mãe e o bebê é que vai se formando uma modalidade de aprendizagem que será observada em condutas posteriores da criança e do adulto. Muitos problemas são criados ou intensificados pela situação emocional insatisfatória do lar.

Para que a criança evolua cognitivamente é necessário que esta tenha suas necessidades satisfatoriamente atendidas, num primeiro instante, e que aos poucos seja permitido a ela um desligamento gradativo. Tal desligamento vai provocar na criança uma "falta", e por conta desta falta será instaurado o desejo, pois desejamos aquilo que não temos. Assim, será em função desse desejo que se iniciará o processo cognitivo.

Segundo Saltini (apud Araújo, 2014, p.133), "Não haverá um potencial cognitivo se não houver um corte nos cordões psicológicos".

É necessário, também, observarmos as características da relação família $\mathrm{x}$ criança. Por exemplo: se existe estímulo à dependência ou se existe uma relação onde a família oferece condições para que haja um fortalecimento da personalidade do sujeito, que constitui condição básica para um desenvolvimento cognitivo compatível com as estruturas cognitivas.

Certos comportamentos parentais tendem a se correlacionar com alguns traços de personalidade e características comportamentais da criança. Existem pais que se relacionam com seus filhos de forma autoritária, provocando na criança uma tendência a se comportar de forma passiva, onde lhe é negado a livre expressão do desejo:

Uma análise das práticas parentais e comportamento infantil ressalta, pois, a existência de uma cadeia complexa de interações entre a criança e seus pais, onde se constata uma influência recíproca entre ambos, onde tanto a qualidade do comportamento materno seria afetada pelas características e comportamentos do filho, como também o comportamento parental resultaria em experiências diversas para a criança, com importantes influencias em todo o seu desenvolvimento. (ALENCAR, 2010, p.155).

As relações que se estabelecem entre pais e filhos recebem influencias de diversas variáveis que podem contribuir positiva ou negativamente para a formação da criança:

As características da criança - além da idade e do sexo, suas características de personalidade e sua posição na constelação familiar, são variáveis que influenciam o comportamento dos pais em relação a seus filhos e consequentemente o autoconceito que a criança constrói. Existe uma expectativa geral de que ela exiba comportamento diferente e assuma papéis diferentes dependendo de seu sexo. (ALENCAR, 2010, p.155).

Em nosso contexto social, observase que a independência, iniciativa e sucesso são enfatizados para meninos, ao passo que a obediência, responsabilidade $\mathrm{e}$ dependência são características consideradas mais apropriadas para as meninas. Embora se espere que os meninos sejam mais rebeldes e inconformistas, tais comportamentos são inaceitáveis em muitas situações sociais, como na escola, por exemplo.

Nos anos iniciais da escolaridade, quando o aluno do sexo masculino se encontra em processo de identificação com a figura masculina adulta, é que experimenta na escola um conflito diante da imposição de um papel passivo que ele não deseja assumir. Isto tem efeitos no comportamento do menino que, de modo 
geral, apresenta um rendimento escolar inferior ao das meninas, relevando maior falta de atenção, comportamento problemático e desajustamento escolar. (PERALVA, 2010, p).

Crianças dóceis, irritáveis, ou hiperativas provocam reações diversas por parte dos pais. Estudos comprovam que os primogênitos recebem mais atenção, são mais pressionados no sentido de maior realização e responsabilidade em relação aos outros irmãos, enquanto que os caçulas recebem atenção especial

O que me faz adotar a hipótese que o desinteresse apresentado por alguns alunos não é exclusivamente causado por fatores internos (responsabilidade única do sujeito), e sim que podem existir fatores múltiplos que vêm contribuir para a construção do interesse ou desinteresse do aluno pelo aprendizado escolar.

De acordo com os dados observados neste trabalho, pode-se realizar algumas reflexões que parecem confirmar as hipóteses levantadas. Ao final de pode-se observar a existência de características distintas entre os sujeitos estudados, mesmo que, em alguns aspectos os mesmos apresentassem algo em comum. (DANTAS, 2012, p. 151)

Portanto, não é possível enquadrálos fielmente no perfil previamente traçado pela professora, tanto para alunos interessados quanto para os desinteressados.

Concordo com a ideia de que o interesse pelo aprendizado requer envolvimento afetivo nos ambientes familiar e escolar. Dantas (2012, p. 148) afirma que:

A afetividade depende para evoluir, de conquistas realizadas no plano da inteligência, e viceversa e que as relações humanas estão permeadas do caráter afetivo, ao citar: "quando ainda não é possível a ação cooperativa que vem da articulação de pontos de vista bem diferenciados, o contágio afetivo cria os elos necessários à ação coletiva.

Por se acreditar que cada sujeito é capaz de estruturar sua própria inteligência adaptativa e seu próprio conhecimento, numa troca constante com o meio, e por valorizarmos as relações afetivas como sendo fundamental para a formação do sujeito.

\section{CONSIDERAÇÕES FINAIS}

Acredita-se que a família é a primeira ambiente em que a criança possa ter acesso não só a conhecimentos, mas também, à formação de novos conhecimentos assim como mediadores de leitura.

Uma família que comtempla uma criança com o hábito da leitura a introduz em um universo da literatura abre o seu universo para novos conhecimentos e para o mundo da imaginação. Só dessa forma será possível a família contribuir ativamente para a promoção da competência enciclopédica e da competência literária dos mais novos, participando verdadeiramente na promoção da sua educação literária.

Com o desenvolvimento deste artigo foi possível integrar a produção científica a influência que a família pode ter no desenvolvimento do hábito da leitura, e com isso foi possível destacar que a família tem um papel de ser a primeiras mediadoras de leitura, mas também como estimuladoras de uma educação literária das crianças.

Assim, com o desenvolvimento deste artigo foi possível compreender que a família pode tem um papel fundamental e 
importante no desenvolvimento da criança leitora e nos hábitos da leitura.

Espera-se que este estudo possa ser mais um veículo que some conhecimento científico e que este sirva de interesse para

\section{REFERÊNCIAS}

ALENCAR, Maria de Jesus Queiroz. O trabalho pedagógico do professor de alunos com transtorno do deficit de atenção/hiperatividade: propostas de intervenção em três escolas da rede pública municipal de Fortaleza. 2010. 283f. Universidade Federal do Ceará, Faculdade de Educação, Programa de Pós-Graduação em Educação Brasileira, Fortaleza-CE, 2010.

ARAÚJO, P. F. C. DE.; A psicopedagogia seria uma possibilidade para o enfrentamento das dificuldades de aprendizagem? Faculdade de humanidades de Direito da Universidade Metodista de São Paulo, São Bernardo do Capo, 2014.

Balça, A.; Azevedo, F.; Barros, L. (2017). A formação de crianças leitoras: a família como mediadora de leitura. Revista de Educação Pública, 26(63), 713-727

BRASIL. Estatuto da Criança e do Adolescente, Câmera dos Deputados, Lei no 8.069, de 13 de julho de 1990. DOU de 16/07/1990 - ECA. Brasília, DF.

Ministério da Educação, (1996).

Parâmetros Curriculares Nacionais para o Ensino Fundamental. Brasília, MEC/SEF.

Portaria normativa n. 9, de 30 de junho de 2009. Institui o Plano Nacional de Formação de Professores da Educação Básica (PARFOR). Diário Oficial da União, Brasília, DF: MEC, 1 jul. 2009. futuras pesquisas relacionadas a importância da família na criação de um aluno leitor.

CASARIN, N. E. F.; família e aprendizagem escolar. 2007. Dissertação de mestrado da Faculdade de Física da Pontifícia Universidade Católica do Rio Grande do Sul, do Rio Grande do Sul. 2007.

CHAVES, L. D. O uso de ambiente virtual de aprendizagem, como estratégia de ensino, por meio de metodologia WebQuest em cursos de graduação em enfermagem. São Paulo, 2013.

COLEMAN, J.F. Spring Forest qigong and chronic pain: making a difference Journal of Holistic Nursing (2010) Pensilvânia.

COSTA, A; F. COSTA, M. de F. B. Metodologia da Pesquisa: Conceitos e Técnicas. Rio de Janeiro: Inter-ciência, 2010.

DANTAS, Tania. Formação de professores da EJA: Uma experiência pioneira na Bahia. Revista da FAEBA: Educação e Contemporaneidade, Salvador, v. 21, n. 37, p.147-162, jan./jun. 2012

DURHAM, E. R. Desigualdade educacional e cotas para negros nas universidades. Novos Estudos. CEBRAP, S. Paulo, v. 66, p. 3-22, 2003.

FERNANDES, A. A inteligência Aprisionada. Porto Alegre: Artmed, 2014.

GROSSI, E. P.; BORDIM, J. Paixão de aprender. $2^{\mathrm{a}}$ ed. Petrópolis: Vozes, 2013. 
HOFFMANN, J. Avaliar para promover: as setas do caminho. Porto Alegre:

Mediação, 2013.

MANSINE, E.F.S. Ação da psicologia na escola. São Paulo: Cortez e Moraes, 2015.

MONTANDON, C., (2001). Algumas tendências atuais nas relações FamíliasEscola. Oeiras: Celta Editora. 153-167. 2001.

C., e PERRENOUD, P. Entre pais e professores um diálogo impossível. Oeiras: Celta Editora. 153-167, 2011.

PERALVA, A. A generalização da violência como modo de regulação das interações humanas na região metropolitana do Rio de Janeiro: a violência juvenil. São Paulo, Relatório de Pesquisa/CNPq, mimeografado. 2010.

PILÃO, J. M. O construtivismo. São Paulo: Edições Loyola, 2015.

ROMÃO, J. E. Avaliação Dialógica: Desafios e Perspectiva. São Paulo: Cortez, 2012.
ROMANELLI, G. Pais, filhos, alunos: famílias de camadas populares e a relação com a escola. In: Pinho SZ, org. Formação de educadores: o papel do educador e sua formação. São Paulo: Editora Unesp; 2010. p.371-82.

SAMPAIO, S Freitas. Transtornos e dificuldades de Aprendizagem. RJ; Wak Ed. 2014.

SARACENO B; ASIOLI F, GIANNI T. Manual de saúde mental. São Paulo: Hucitec; 1994.

SILVA, C. L. C. A criança na Linguagem: enunciação e aquisição; Pontes, 2008.

Gatti, B.; Barretto, E. S. S. Professores do Brasil: impasses e desafios. Brasília, DF: UNESCO, 2009.

VASCONCELOS, C. do S. Construção do conhecimento em sala de aula. Caderno Pedagógico do Libertad. São Paulo: Liberdade, 2011.

VEIGA, I. P. A. (Org.) Escola: espaço do projeto político-pedagógico. 4. ed. Campinas: Papirus, 2014. 